detecting it. Women with such problems could be treated by general practitioners or be referred for specialist treatment, though in this study comparatively few women expressed a wish for help.

Thanks are expressed to Drs M K Anscombe, M J V Bull, S R Byrne, P Lawrence, H D Leggatt, A I M Neill, D H Richards, A Taylor, and S J Wood, who kindly allowed their general practice patients to be seen. We are also grateful to Drs P Cooper, J Bancroft, and J Ferguson for advice; Virginia Mander for secretarial help; and Ann Day, Alison Bond, and Clare Passingham for carrying out the interviews and helping with data analysis. Financial support was provided by the Oxford Regional Health Authority and Oxfordshire Health Authority.

\section{Appendix}

Questions included in sexual inquiry

(1) What would be your average frequency of sexual intercourse over the past three months?

(2) Over the past three months on what proportion of occasions that you made love did you find it a pleasant experience?

(3) Over the past three months on what proportion of occasions that you made love did you find it an unpleasant experience?

(4) How often during the past three months have you experienced a climax during sex?

(5) How often during the past three months have you had any difficulties in sexual intercourse because of discomfort (for example, pain)?

(6a) Do you experience vaginal dryness?

(6b) If yes does it present a problem in sexual intercourse?

(7) Over the past three months have you ever not had sexual intercourse because of excessive menstruation?

(8) Has your interest in sex changed during the past year?

(9) Has your interest in having sex been low during the past year?

(10) Has your partner experienced any difficulties with sex? (Probe impotence, premature ejaculation, low sex drive, etc)
(11) Have you had problems with sex because of the way you get on with your partner in general? (Probe conflict, quarrelling, apathy, drifting apart)

(12) How satisfied are you with your sexual relationship overall?

(13) Do you regard yourself as having a problem with sex?

(14) If help were available for such a problem would you like such help?

\section{References}

1 Kinsey AC, Pomeroy WB, Gebhard PH. Sexual behaviour in the human female. Philadelphia Saunders, 1953.

Frank E, Anderson C, Rubenstein D. Frequency of sexual dysfunction in "normal" couples. N Englf Med 1978;299:111-5.

3 Garde K, Lunde I. Female sexual behaviour: a study in a random sample of 40-year-old women. Maturitas 1980;2:225-40.

4 Garde K, Lunde I. Social background and social status: influence on female sexual behaviour. A random sample of 40-year-old Danish women. Maturitas 1980;2:241-6.

5 Levine SB, Yost MA. Frequency of sexual dysfunction in a general gynecological clinic: an epidemiological approach. Arch Sex Behav 1976;5:229-38.

6 Moore B, Gustafson R, Studd J. Experience of a National Health Service menopause clinic Curr Med Res Opin 1975;3(suppl 3):42-55.

7 Weissman MM, Paykel ES. The depressed woman: a study of social relationships. Chicago: University of Chicago Press, 1974.

8 Gath D, Osborn $M$, Bungay G, et al. Psychiatric disorder and gynaecological symptoms in middle aged women: a community survey. BrMed f 1987;294:213-8.

Gath D, Cooper P, Day A. Hysterectomy and psychiatric disorder: I. Levels of psychiatric morbidity before and after hysterectomy. Br F Psychiatry 1982;140:335-50.

10 Cooper P, Gath D, Fieldsend R, Rose N. Psychological and physical outcome after elective tubal sterilisation. F Psychosom Res 1981;25:357-60.

11 Wing JK, Cooper J, Sartorius N. The measurement and classification of psychiatric symptoms. Cambridge: Cambridge University Press, 1974.

12 Eysenck HJ, Eysenck SBG. Manual of the Eysenck personality inventory. London: University of London Press, 1964.

13 Cooper P, Osborn M, Gath D, Feggetter G. Evaluation of a modified self-report measure of social adjustment. Br f Psychiatry 1982;141:68-78.

14 Nie NH, Hull HC, Jenkins JG, Steinbrenner K, Bent DH. SPSS: statistical package for the social sciences. New York: McGraw-Hill, 1975

15 Wing JK, Mann SA, Leff JP, Nixon JM. The concept of a "case" in psychiatric population surveys. Psychol Med 1978;8:203-17.

16 Suthurst JR. Sexual dysfunction and urinary incontinence. Br f Obstet Gynaecol 1979;86:387-8. 17 Bungay GT, Vessey MP, McPherson CK. Study of symptoms in middle life with special reference to the menopause. $\mathrm{Br}$ Med $\mathrm{F} 1980 ; 281: 181-3$.

(Accepted I December 1987)

\title{
Outcome of pregnancy in underweight women after spontaneous and induced ovulation
}

\author{
$Z$ M VAN DER SPUY, P J STEER, M MCCUSKER, S J STEELE, H S JACOBS
}

\begin{abstract}
Low maternal weight before pregnancy and poor weight gain during pregnancy are known to result in an increased prevalence of low birthweight infants. Low body weight is also an important cause of amenorrhoea. The hypothesis that amenorrhoeic underweight women who become pregnant after induction of ovulation are more at risk of delivering low birthweight infants than
\end{abstract}

Cobbold Laboratories and Department of Obstetrics and Gynaecology, University College and Middlesex School of Medicine, London WIN 8AA

Z M VAN DER SPUY, PHD, MRCOG, research assistant and honorary senior registrar

S J STEELE, FRCS, FRCOG, director, academic department of obstetrics and gynaecology

H S JACOBS, MD, FRCP, professor of reproductive endocrinology

Department of Obstetrics and Gynaecology, St Mary's Hospital Medical School, London W2 1PG

P J STEER, MD, MRCOG, senior lecturer and honorary consultant

M MCCUSKER, BSC, MMEDSCI, research assistant

Correspondence to: Ms Z M van der Spuy, Gynaecological Endocrine Laboratory Department of Obstetrics and Gynaecology, University of Cape Town Medical School, Groote Schuur Hospital, Observatory, Cape Town 7925, Republic of South Africa. underweight women who ovulate spontaneously was investigated. Forty one pregnant women in whom ovulation had been induced and 1212 in whom ovulation was spontaneous were studied. Women ovulating spontaneously whose weight was normal and who showed good weight gain during pregnancy ( $>450 \mathrm{~g}$ a week) had the lowest incidence $(6 \%)$ of babies who were small for gestational age. Underweight women (body mass index $<19 \cdot 1$ ) who ovulated spontaneously had a threefold increased risk of delivering babies who were small for gestational age $(18 \%)$. Overall, the women in whom ovulation had been induced had an even higher risk of babies who were small for dates $(25 \%)$, and this risk was greatest $(54 \%)$ in those who were underweight.

The outcome of pregnancy is related to weight before conception, which in many cases reflects nutritional state; lack of spontaneous ovulation indicates an increased risk of producing a small for dates infant. The most suitable treatment for infertility secondary to weight related amenorrhoea is therefore dietary rather than induction of ovulation.

\section{Introduction}

The commonest cause of amenorrhoea resulting in infertility in our patients is subnormal body weight. The developing fetus is vulnerable to maternal dietary deficiencies and, contrary to earlier 
beliefs, may be severely affected by maternal undernutrition. With increasing emphasis on preventive medicine factors that adversely affect the outcome of pregnancy and that may be treated before conception or antenatally are of concern to obstetricians and paediatricians.

Low maternal weight before pregnancy and poor weight gain during pregnancy correlate with an increased prevalence of infants with low birth weight. ${ }^{1-4}$ Infants who are small for dates or growth retarded are at a greater risk during the neonatal period than well grown babies and may suffer from long term sequelae such as permanently reduced intellectual and physical development. ${ }^{5.7}$

We studied the outcome of pregnancy in two groups of women who were delivered in London teaching hospitals. One group comprised 1212 women who ovulated spontaneously and the second group 41 in whom ovulation had been induced to treat anovulatory infertility. We determined the effect of "undernutrition" before pregnancy on birth weight in both groups and attempted to assess whether the anovulatory women were particularly at risk of delivering infants whose growth was retarded.

\section{Patients and methods}

We studied two groups of women; one group comprised 1212 non-obese women with singleton pregnancies after spontaneous ovulation who had booked for antenatal care before 16 weeks' gestation and were delivered at St Mary's Hospital. Obese women, defined as those with a body mass index (weight $(\mathrm{kg}) /\left(\right.$ height $\left.(\mathrm{m})^{2}\right)$ ) exceeding $25 \cdot 1$, were excluded from the study.

The second group consisted of 41 women from our infertility clinics who had presented with either amenorrhoea or oligoamenorrhoea and had required induction of ovulation to treat anovulatory infertility. All had been fully investigated before treatment and had failed to respond to clomiphene citrate. Twenty three of the women received human menopausal gonadotrophin daily until adequate follicular development was achieved; ovulation was subsequently triggered with a single dose of human chorionic gonadotrophin when the follicular diameter was $18 \mathrm{~mm}$ or more. The remaining 18 women were treated with luteinising hormone releasing hormone, which was administered in subcutaneous pulses with a miniaturised automatic infusion system. ${ }^{8}$ If menstruation occurred the treatment was continued uninterrupted into the subsequent cycle until the patient conceived; all the women conceived within six cycles of treatment. The response to treatment was assessed by monitoring follicular development with serial pelvic ultrasound imaging and by serial measurements of serum gonadotrophin, oestradiol, and progesterone concentrations.

The social class and smoking habits of all patients were recorded. Weekly weight gain was determined for each patient by subtracting the weight at the time of booking from the final antenatal weight and dividing by the number of complete weeks from booking to delivery. A body mass index of $19 \cdot 1-25 \cdot 1$ at the time of booking was classified as normal weight and that below $19 \cdot 1$ as underweight. ${ }^{9}$ We regarded a weekly weight gain after 16 weeks' gestation of $450 \mathrm{~g}$ or more as satisfactory. ${ }^{10} 11$

The birth weight of each infant, with corrections for sex, parity, gestational age, and maternal height, was plotted against the nomograms of Altman and Coles. ${ }^{12}$ Babies whose weight was below the 10th centile were defined as small for dates and therefore potentially growth retarded. Delivery before 37 completed weeks of pregnancy was regarded as preterm.

Differences between groups were analysed with the $\chi^{2}$ test unless otherwise stated.

\section{Results}

\section{OUTCOME OF PREGNANCY AFTER SPONTANEOUS OVULATION}

The table shows the correlation of maternal body mass index with birth weight on or below the 10th centile. There was a significantly higher incidence of babies who were small for gestational age when the mothers were underweight with a body mass index of $<19 \cdot 1(33 / 179 ; 18 \%)$ than when they were of normal weight with an index $\geqslant 19 \cdot 1(97 / 1033 ; 9 \%)\left(\chi^{2}=13, \mathrm{df}=\right.$ $1, \mathrm{p}<0.0005 ;$ difference in proportions $=0.09,95 \%$ confidence interval 0.03 to $0 \cdot 15$ ).

Weight gain was known for 1027 of the 1033 women of normal weight (in six cases weight at the last visit to the clinic had not been recorded). The risk for a mother of normal weight of having a baby who was small for dates was significantly lower if her weekly weight gain exceeded $450 \mathrm{~g}$ (only $6 \%$ (25/ 435 ) compared with $12 \%(72 / 592)$ if weight gain was $450 \mathrm{~g}$ or less; $\chi^{2}=12 \cdot 1$, $\mathrm{df}=1, \mathrm{p}<0.001$; difference in proportions $=0.06,95 \%$ confidence interval
0.03 to $0 \cdot 10$ ). Weight gain was known for all 179 of the underweight women In these women, too, a weekly weight gain exceeding $450 \mathrm{~g}$ was associated with a lower incidence of babies who were small for gestational age (15\% (10/ 66) $v 20 \%(23 / 113)$ in women with a weight gain of $450 \mathrm{~g}$ or less), but the difference was not significant. The incidence of babies who were small for gestational age was, however, still significantly higher in underweight women with good weight gain $(15 \%)$ than in women of normal weight with good weight gain $(6 \%)\left(\chi^{2}=7 \cdot 8, \mathrm{df}=1, \mathrm{p}<0.01\right.$; difference in proportions $=$ $0 \cdot 09,95 \%$ confidence interval 0.005 to $0 \cdot 18$ ).

Women who were underweight had an increased risk of preterm delivery $(10 \% ; 18 / 179)$ compared with women of normal weight $(5 \% ; 51 / 1033)\left(\chi^{2}=\right.$ $7 \cdot 4, \mathrm{df}=1, \mathrm{p}<0.01$; difference in proportions $=0.05,95 \%$ confidence interval $0 \cdot 005$ to $0 \cdot 10$ ).

Smoking habits were recorded for $167(93 \%)$ of the underweight women and for 1017 (98\%) of the women of normal weight; the proportion of smokers was similar in both groups $(44(26 \%)$ of the underweight women and $248(24 \%)$ of the normal women smoked). Smoking was associated with a significant increase in the incidence of babies who were small for gestational age born to women of normal weight $(17 \%(41 / 248)$ among smokers compared with 7\% (55/769) among non-smokers; $\chi^{2}=19 \cdot 0, \mathrm{df}=1$, $\mathrm{p}<0.0005$; difference in proportions $=0.10,95 \%$ confidence interval 0.04 to $0 \cdot 14)$. A similar increase was associated with smoking in the underweight women, $25 \%(11 / 44)$ of those who smoked having small for dates babies compared with $14 \%(17 / 123)$ who did not, but the difference was not significant $\left(\chi^{2}=2 \cdot 9, \mathrm{df}=1, \mathrm{p}<0 \cdot 1\right.$; difference in proportions $=0 \cdot 11,95 \%$ confidence interval -0.03 to 0.25 )

Social class was recorded for 1055 women; 894 of the $1033(86 \%)$ women of normal weight and 161 of the $179(90 \%)$ underweight women. The remainder could not be classified. Of the women of normal weight at booking, $431(48 \%)$ were in social class I or II, $277(31 \%)$ in social class III and $186(21 \%)$ in social class IV or V. Of the women who were underweight, $79(49 \%)$ were in social class I or II, $47(29 \%)$ in social class III, and $35(22 \%)$ in social class IV or V. These distributions were not significantly different $\left(\chi^{2}=0 \cdot 22, \mathrm{df}=2\right)$. The effects of maternal weight and weight gain on birth weight could not be explained by smoking habits or social class as these were not significantly different between the normal weight and underweight women.

Two intrauterine deaths occurred in the women ovulating spontaneously; one was due to congenital abnormality and the other was presumed to be due to placental insufficiency. No other perinatal deaths were recorded in this group.

\section{OUTCOME OF PREGNANCY AFTER INDUCTION OF OVULATION}

The overall risk of producing a baby who was small for gestational age was significantly higher in women who had required induction of ovulation than in those ovulating spontaneously $\left(25 \%(10 / 41) v 11 \%(130 / 1212) ; \chi^{2}=7 \cdot 5\right.$, $\mathrm{df}=1, \mathrm{p}<0.01$; difference in proportions $=0 \cdot 14,95 \%$ confidence interval 0.004 to $0 \cdot 27$ ).

Thirteen of the 41 women $(32 \%)$ whose ovulation was induced were underweight at booking, a significantly higher proportion than in the women ovulating spontaneously $(15 \% ; 179 / 1212)\left(\chi^{2}=8.8, \mathrm{df}=1, \mathrm{p}<0.005\right.$; difference in proportions $=0 \cdot 17,95 \%$ confidence interval 0.03 to $0 \cdot 31$ ).

Women who had required induction of ovulation had five times the risk of having a baby who was small for gestational age as women of normal weight $(54 \%(7 / 13) v 11 \%(3 / 28)$; difference in proportions $=0.43,95 \%$ confidence interval 0.14 to $0.73, \mathrm{p}=0.005$, Fisher's exact test) and 10 times the risk of normal weight women with spontaneous ovulation and good weight gain $6 \%$ $(25 / 435) ; \chi^{2}=44, \mathrm{df}=1, \mathrm{p}<0.0005$; difference in proportions $=0.48,95 \%$ confidence interval $0 \cdot 21$ to $0 \cdot 75$ ).

The protective effect of good weight gain in the patients requiring induction of ovulation was similar to that in the women who ovulated spontaneously, although because of small numbers it was not significant. When the weight gain was $>450 \mathrm{~g}$ a week only one of eight $(13 \%)$ babies was

Distribution of babies with birth weight on or below 10 th centile born to normal weight and underweight women

\begin{tabular}{lcccccccc}
\hline & \multicolumn{8}{c}{ Maternal body index } \\
\cline { 2 - 9 } & $<18 \cdot 1^{\star}$ & $18 \cdot 1^{\star}-$ & $19 \cdot 1-$ & $20 \cdot 1-$ & $21 \cdot 1-$ & $22 \cdot 1-$ & $23 \cdot 1-$ & $24 \cdot 1-25 \cdot 0 \dagger$ \\
\hline No of women & 102 & 77 & 144 & 210 & 184 & 217 & 155 & 123 \\
No(\%) of babies & $21(21)$ & $12(16)$ & $15(10)$ & $23(11)$ & $20(11)$ & $14(6)$ & $17(11)$ & $8(7)$ \\
\hline
\end{tabular}

^Underweight.

+Women with body mass index $>25 \cdot 0$ excluded

$\chi^{2}=18 \cdot 7, \mathrm{df}=7, \mathrm{p}<0 \cdot 025$ 
small for gestational age, compared with nine of 31 (27\%) when weight gain was $\leqslant 450 \mathrm{~g}$. Notably, however, only eight of 41 women $(20 \%)$ who required induced ovulation compared with 501 of $1206(42 \%)$ who ovulated spontaneously showed good weight gain $\left(\chi^{2}=8, \mathrm{df}=1, \mathrm{p}<0.005\right.$; difference in proportions $=0 \cdot 22,95 \%$ confidence interval $0 \cdot 1$ to $0 \cdot 34$ )

The mean weekly weight gain in the 13 underweight women in whom ovulation was induced was not significantly different from that in the 28 women of normal weight (312 (SD 110) g $v 341$ (102) $\mathrm{g} ; t=0.83$ ). The 13 underweight women, however, had a significantly lower mean weekly weight gain than the 185 underweight women who ovulated spontaneously (312(110) g v 421 (149) $\mathrm{g}$; difference between means $=109 \mathrm{~g}, 95 \%$ confidence interval 26 to $192 \mathrm{~g} ; t=-2 \cdot 58, \mathrm{df}=190, \mathrm{p}<0.005)$. This difference was also seen when the women of normal weight in both the groups were compared (mean weight 341 (102) $\mathrm{g}(\mathrm{n}=28) v 438(150) \mathrm{g}(\mathrm{n}=1027)$; difference between means $=97 \mathrm{~g}, 95 \%$ confidence interval 41 to $153 \mathrm{~g} ; t=-3 \cdot 4, \mathrm{df}=1053$, $\mathrm{p}<0.0005))$.

All the women who required induction of ovulation were in social class I, II, or III (non-manual). The absence of women in social classes IV and V was significantly different from the distribution of women ovulating spontaneously, of whom 221 were in social classes IV and V $(p=0.00008$, Fisher's exact test). No perinatal deaths occurred in this group.

\section{Discussion}

The most important effect of undernutrition on reproductive performance is on the outcome of pregnancy. The energy cost of pregnancy in well nourished women has been variously estimated as 27120 (SD - 2175) kcal (89 (9) MJ), ${ }^{13} 36000 \mathrm{kcal}(151 \mathrm{MJ}),{ }^{10}$ and $46500 \mathrm{kcal}(195 \mathrm{MJ}),{ }^{11}$ and women who start pregnancy undernourished and continue to have an inadequate dietary intake are at a considerable nutritional disadvantage.

As the weight gained by the mother during the first trimester is trivial we regarded the body mass index at the time of booking as equivalent to the weight before pregnancy ${ }^{10}$; if this resulted in incorrect classification the number of underweight women would tend to have been underestimated. The normal ranges were derived from the life tables of the Metropolitan Life Insurance Company of 1958 and are similar to those quoted by Garrow. ${ }^{9}$ In previous studies a weight gain during pregnancy of $10 \cdot 9-12.3 \mathrm{~kg}$ resulted in the lowest perinatal mortality rates; we therefore considered a weekly weight gain of $450 \mathrm{~g}$ or more to be acceptable in pregnancy. ${ }^{1014}$

The underweight women who ovulated spontaneously had the expected increased incidence of infants who were small for gestational age,${ }^{415-18}$ and the protective effect of adequate weight gain was seen in both the normal weight and underweight women. ${ }^{16}$ The underweight women also had almost twice the incidence of preterm delivery found in women of normal weight. Underweight women in other studies had higher rates of preterm labour, premature rupture of membranes, endometritis, and anaemia. ${ }^{15} 18$

In the women who required induction of ovulation a body mass index below $19 \cdot 1$ at the time of booking was associated with a fivefold increase in the risk of having a baby with a birth weight below the 10th centile. This suggests strongly that underweight women who develop amenorrhoea should be regarded as particularly at risk of having a growth retarded infant. Of particular interest was the failure of these women to gain weight adequately during pregnancy, suggesting that the dietary disturbance that predated the anovulatory infertility persisted into pregnancy despite the counselling and increased antenatal care that these patients receive.

Self imposed dietary restriction with weight loss accounts for 25 $35 \%$ of patients presenting with amenorrhoea at gynaecological endocrine clinics in developed countries ${ }^{1920}$; in our study the proportion of underweight women in the group with amenorrhoeic infertility was double that in the group who ovulated spontaneously. Moreover, the weight gain during pregnancy among the infertile women was significantly lower than that among the fertile women.

Information on the effects of nutritional deprivation on the outcome of pregnancy in animals shows that it may result in gross neurological and developmental problems, with stunted growth and increased morbidity and mortality in the offspring. These effects are associated with a deficit in the final numbers of cells in the organs of these animals. ${ }^{21}{ }^{22}$ Furthermore, a reduction in numbers of cells has been reported in growth retarded human fetuses. ${ }^{23}$ During the three trimesters of human pregnancy roughly 44 cell doublings occur, about 35 of these in the first 13 weeks. An insult in the first trimester has a potentially far more sinister outcome than one later in pregnancy, and the fetus is vulnerable at a stage when pregnancy has not yet been diagnosed. ${ }^{23}$ The onset of growth retardation late in pregnancy seems to cause a reduction in the size of cells rather than the irreversible reduction in cell numbers that is caused by earlier insults.

Dietary supplementation is valuable in underweight pregnant women but is not indicated in pregnant women of normal weight who are well ${ }^{25}{ }^{26}$ It would be convenient biologically if poor nutrition always caused infertility, but this is not always the case.

As part of preconception care and infertility treatment it is important to define the point at which the risk of fetal compromise becomes unacceptable. Frisch suggested that a ponderal (body mass) index of 20.8 should be "the infertility threshold" for white North American women, ${ }^{27}$ and Fries gave a weight of 52 (SD 6.3) kg as the threshold for infertility in Swedish women. ${ }^{28}$ Rush $e t$ al in a study of indigent black women in New York with a mean body mass index of 20.6 (SD 2.3) before pregnancy showed an association between low body mass index and an unfavourable outcome and increased perinatal morbidity. ${ }^{29}$ Woods, in a study of primigravidas in Cape Town, found that low maternal body mass index correlated with an excess of growth retarded infants and showed that maternal "fatness," as measured by skinfold thickness and body mass index, rather than muscle volume was the main determinant of the outcome of pregnancy. ${ }^{17} 30$ Maternal reserves of energy and nutritional supply are therefore of paramount importance in determining intrauterine growth. ${ }^{17}{ }^{31} 32$ Ounsted et al found that maternal height affected the chances of having an infant who was small for dates; this finding may be due to the general nutritional and social standards of these patients being higher than those in the other studies, thus giving height greater importance as a risk factor. ${ }^{33}$

Intrauterine growth retardation may result in antenatal and intrapartum asphyxia and neonatal complications such as hypoglycaemia and hypothermia, and physical and neurological development may be delayed. When retarded intrauterine growth is evident before 26 weeks' gestation fetuses seem to be more at risk of long term damage. ${ }^{14243435}$

In conclusion, we have shown that the nutritional state of women before conception is related to the outcome of pregnancy and is particularly important in underweight women with amenorrhoea. The development of amenorrhoea seems to be a biological signal that should be heeded; we suggest that anovulatory infertility caused by low weight should be treated by diet. Inducing ovulation in an underweight woman carries an excess risk to the fetus and should be deferred until the woman has achieved her normal body weight. This in itself may result in resumption of natural ovulation rendering treatment unnecessary.

$M M c C$ was seconded from the Hera unit of the Spastics Society. The funding received from the Spastics Society is gratefully acknowledged. We thank Mr S Isaacs of the department of medical informatics, Groote Schuur Hospital, for his help with the statistical analyses.

\section{References}

1 Singer JE, Westphal M, Niswander K. Relationship of weight gain during pregnancy to birthweight and infant growth and development in the first year of life. Obstet Gynecol 1968;31:417-23.

2 Lechtig A, Yarbrough C, Delgado H, Habicht J-P, Martorell R, Klein RE. Influence of maternal nutrition on birth weight. Am f Clin Nutr 1975;28:1223-33.

3 Luke B, Dickinson C, Petrie RH. Intrauterine growth: correlations of maternal nutritional status and rate of gestational weight gain. Eur f Obstet Gynaecol Reprod Biol 1981;12:113-21.

4 Naeye RL. Weight gain and the outcome of pregnancy. Am f Obstet Gynecol 1979;135:3-9.

5 Fitzhardinge PM, Steven EM. The small-for-date infant. I. Later growth patterns. Pediatric 1972;49:671-81.

6 Fitzhardinge PM, Steven EM. The small-for-date infant. II. Neurological and intellectual sequelae. Pediatrics 1972;49:50-7.

Hill RM, Verniaud WM, Deter RL, et al. The effect of intrauterine malnutrition on the term infant. Acta Paediatr Scand 1984;73:482-7.

8 Mason $\mathrm{P}$, Adams J, Morris DV, et al. Induction of ovulation with pulsatile luteinising hormone releasing hormone. $\mathrm{Br} \mathrm{Med} \mathcal{f}$ 1984;288:181-5.

9 Garrow JW. Treat obesity seriously. A clinical manual. Edinburgh: Churchill Livingstone, 1981.

$10 \mathrm{Hytten}$ FE, Leitch I. The physiology of human pregnancy. Oxford: Blackwell Scientific Publications, 1971. 
11 Forsum E, Sadurskis A, Wager J. Energy maintenance cost during pregnancy in healthy Swedish women. Lancet 1985; i: 107-8.

12 Altman DG, Coles EC. Nomograms for precise determination of birth weight for dates. Br J Obstet Gynaecol 1980;87:81-6.

13 Emerson K, Saxena BN, Poindexter EL. Caloric cost of normal pregnancy. Obstet Gynecol 1972;40:786-94.

14 Niswander KR, Gordon M. The collaborative study of cerebral palsy, mental retardation and other neurological and sensory disorders of infancy and childhood: the women and their pregnancies. Philadelphia: W B Saunders, 1972.

15 Edwards LE, Alton IR, Barrada ME, Hakanson EY. Pregnancy in the underweight woman. Course, outcome, and growth patterns of the infant. Am J Obstet Gynecol 1979;135:297-302.

16 Stein Z, Susser M. The Dutch famine, 1944-1945 and the reproductive process. I. Effects on six indices at birth. Pediatr Res 1975:9:70-6.

17 Woods DL. Maternal, infant, and placental size at birth. A study of firstborn term infants and their mothers in Cape Town. [Dissertation]. Cape Town, South Africa: University of Cape Town, 1984. $164 \mathrm{pp}$

18 Niswander K, Jackson EC. Physical characteristics of the gravida and their association with birth weight and perinatal death. Am $\mathcal{J}$ Obstet Gynecol 1974;119:306-13.

9 Knuth UA, Hull MGR, Jacobs HS. Amenorrhoea and loss of weight. Br $\mathcal{F}$ Obstet Gynaecol 1977;84:801-7.

20 Thomson JE, Baird SG, Thomson JA. Thyroid function in dietary amenorrhoea. Clin Endocrinol (Oxf) 1977;7:383-8.

21 Winick $M$, Noble A. Cellular response in rats during malnutrition at various ages. $\mathcal{J}$ Nutr 1966;89:300-6.

22 Leader A, Wong $\mathrm{KH}$, Deitel M. Maternal nutrition in pregnancy. Part I: a review. Can Med Assoc $\mathcal{7} 1981 ; 125: 545-9$.
23 Widdowson EM, Crabb DE, Milner RDG. Cellular development of some human organs before birth. Arch Dis Child 1972;47:652-5.

24 Wynn M, Wynn A. The prevention of handicap of early pregnancy origin. London: Foundation for Education and Research in Childbearing, 1981

25 Prentic AM, Whitehead RG, Watkinson M, Lamb WH, Cole TJ. Prenatal dietary supplementation of African women and birth weight. Lancet 1983;i:489-92.

26 Lind T. Would more calories per day keep low birthweight at bay? Lancet 1984;i:501-2.

27 Frisch RE. Food intake, fatness and reproductive ability. In: Vigersky R, ed. Anorexia nervosa. New York: Alan R Liss, 1977:343-63.

28 Fries $\mathrm{H}$. Secondary amenorrhoea, self-induced weight reduction, and anorexia nervosa. Acte Psychiatr Scand [Suppl] 1974;248:5-45.

29 Rush D, Stein Z, Susser M. Diet in pregnancy: a randomized controlled trial of nutritional supplements. New York: Al Susser M. Die in

30 Woods DL, Malan AF, Heese HdeV, van Schalkwyk DK. Maternal size and fetal growth. S Afr Med I 1979;56:562-4.

31 Briend A. Do maternal energy reserves limit fetal growth? Lancet 1985;i:38-40.

32 Chiswick ML. Intrauterine growth retardation. BrMed $\mathcal{J}$ 1985;291:845-7.

33 Ounsted M, Moar VA, Scott A. Risk factors associated with small-for-dates and large-for-date infants. Br J Obstet Gynaecol 1985;92:226-32.

34 Low JA, Galbraith RS, Muir D, Killen H, Karchmar J, Campbell D. Intra-uterine growth retardation: a preliminary report of long-term morbidity. Am f Obstet Gynecol 1978;130:534-5.

35 Fancourt R, Campbell S, Harvey D, Norman AP. Follow-up study of small-for-dates babies. BrMed f 1976;i:1435-7.

(Accepted 9 November 1984)

\begin{abstract}
The clinical effects of routinely imaging the renal tract (by intravenous urography and ultrasonography) were evaluated prospectively in 128 consecutive patients with prostatism. Patients with haematuria, previous renal disease, or infection were excluded. Urologists completed a standard questionnaire in the patient's notes stating the diagnosis and the intended management. The patient then had intravenous urography and abdominal ultrasonography, urine was analysed, and plasma urea and serum creatinine concentrations and acid phosphatase activity were determined. From six months to a year later the eventual management was compared with the intended management to see the effect of these routine investigations on the outcome. For four out of 28 patients whose management was intended to be conservative the decision was changed; for only three of them was this because of the results of urography, ultrasonography, and biochemical determinations. For 31 patients the management was to be decided by cystoscopic findings, and for none of these was the final decision altered by the results from the investigations after the initial consultation. Similarly for five patients who were assessed urodynamically the final management was not changed by the results of these investigations. The planned management was changed in three of the remaining 64 patients but not because of the results of the initial investigations.

Thus no indication was found for either routine urography or ultrasonography, but the total abandonment of imaging of the renal tract would be unwise. Patients scheduled for conservative management (about a quarter of the patients in this study) should have ultrasonography to detect unsuspected hydronephrosis, but in all other patients urography or ultrasonography, or both,
\end{abstract}

\footnotetext{
Departments of Diagnostic Radiology and Urology, Northwick Park Hospital and Clinical Research Centre, Harrow, Middlesex HA1 3UJ

GERALD DE LACEY, MA, FRCR, consultant radiologist

STEPHEN JOHNSON, FRCR, senior registrar in radiology

DAVID MEE, FRCS, consultant urologist

Correspondence to: Dr de Lacey.
}

is an unhelpful ritual. Moreover, urography is becoming more expensive, and has a recognised (albeit small) mortality.

\section{Introduction}

Routine intravenous urography remains a common procedure for patients presenting with prostatic symptoms, but controversy exists about this practice. ${ }^{1-6}$ An important drawback when assessing the differing claims is that most surveys on the usefulness of urography have either been retrospective, assessing small numbers of patients, or included patients with acute retention or haematuria, or both Several surveys have concentrated less on the question of who needs to have the urinary tract imaged and more on whether ultrasonography provides as much useful information as urography.$^{7.9} \mathrm{~A}$ recent trend has been to replace routine urography with routine ultrasonography. The purpose of our survey was to assess prospectively the influence on clinical management of both imaging procedures.

\section{Patients and methods}

We studied 128 consecutive patients with prostatic symptoms presenting to this urology outpatient clinic between January 1984 and March 1986 Those patients with a history of haematuria, acute urinary retention, preexisting renal disease, urinary tract infection, and obvious prostatic malignancy were excluded. Also excluded were those who had recently had urography or ultrasonography as this might have led to inadvertent bias from the urologist viewing the films or reading the report.

After clinical assessment and before any investigations the urologist completed a standard questionnaire stamped on to the patient's notes stating the provisional diagnosis and the intended management (fig 1). All patients then had intravenous urography and abdominal ultrasonography of the kidneys, bladder, and prostate and their urine was analysed and plasma urea concentrations, serum creatinine concentration, and acid phosphatase activity determined. Some 45 items of information for each patient were entered on computer sheets.

Between six months and one year later the notes of each patient were reviewed to assess the influence that the investigations had had on the original management decision recorded by the urologist at the first attendance in the outpatient clinic. 